\section{CLAUSURAS: LA SUPOSICIÓN DEL SUJETO, ENTRE FILOSOFÍA Y PSICOANÁLISIS}

\author{
Clausuras. O Pressuposto do Sujeito, entre a Filosofia e a \\ Psicanálise
}

\author{
Cloisters. The Subject's Assumption, between Philosophy and \\ Psychoanalysis
}

\author{
Enceintes. La Proposition du Sujet, entre la Philosophie et la \\ Psychanalyse
}

\begin{abstract}
Resumen
El sujeto, tanto para la filosofía como para el psicoanálisis, "aparece” como una suposición evanescente, ahi donde se expone lo abisal del fundamento metafisico. Proponemos que esto es lo que abre a la filosofía y al psicoanálisis a una interrogación conjunta, a un entre, que el presente trabajo desarrollará: primero, abordando la cuestión del principio en Aristóteles a partir de los conceptos de Arché, ousía e hypokeimenon para después pasar a la cuestión del subjectum y la concepción de las verdades eternas en Descartes y la clausura de la metafisica producida por la crítica de Leibniz a dicha concepción, para finalmente, desarrollar el modo en que Lacan piensa el sujeto del inconsciente a partir del lugar que le ha entregado la tradición metafísica. La invención freudiana del inconsciente supone la metafísica del sujeto (más bien, supone su suposición) y es esa suposición la que lleva a repensar el sentido de su praxis.
\end{abstract}

Palabras clave: ousia; hypokeimenon; subjectum; clausura de la metafísica; cierre del inconsciente; interpretación; transferencia.

\section{Resumo}

O assunto, tanto para a filosofia como para a psicanálise, "aparece" como uma hipótese evanescente abissal em que ele expõe o fundamento metafísico. Supomos que isso é o que abre à filosofia e à psicanálise uma interrogação conjunta à qual este trabalho desenvolverá: em primeiro lugar, ao abordar o princípio de Aristóteles a partir dos conceitos de Arché, ousía e hypokeimenon, passando posteriormente à questão do subjectum e à concepção das verdades eternas em Descartes e do encerramento da metafísica, produzido pela crítica de Leibniz a essa concepção, para, finalmente, desenvolver a maneira pela qual Lacan pensa o sujeito do inconsciente a partir do lugar tem dado a ele a tradição metafísica. A invenção freudiana do inconsciente supõe a metafísica do sujeito (ou melhor, supõe sua suposição), e essa suposição é o que nos leva a repensar o sentido de sua práxis.

Palavras-chave: ousía; hypokeimenon; subjectum; encerramento da metafísica; fechamento do inconsciente; interpretação; transferência.

\section{Abstract}

The issue, both for philosophy as for psychoanalysis, "appears" as an abyssal evanescent hypothesis that it exposes the metaphysical foundation. We assume that this is what opens to

\section{Artigo Original}

\section{Dr. Gianfranco Cattaneo ${ }^{(1)}$}

1) Escuela de Psicología, Universidad Andrés Bello, Viña del Mar (Chile). Becario CONICYT. 
philosophy and psychoanalysis a joint question to which this work will develop: first, to address the principle of Aristotle from the concepts of Arché, ousia and hypokeimenon subsequently passing to the question of subjectum and to the conception of the eternal truths in Descartes and the closure of metaphysics, produced by the criticism of Leibniz to this conception, to finally develop the way in which Lacan thinks the subject of the unconscious from the place has given him the metaphysical tradition. Freud's invention of the unconscious supposes the subject's metaphysics (or rather, assumes his assumption), and this assumption is what leads us to rethink the direction of their practice.

Keywords: ousia; hypokeimenon; subjectum; metaphysics of closure; unconscious closure; interpretation; transfer.

\section{Résumé}

Le thème, tant pour la philosophie comme pour la psychanalyse, " apparaît " comme une hypothèse évanescente et abyssale qui expose le principe metaphysique. On suppose que cela ouvre la philosophie et la psychanalyse à la question laquelle cet article développera: premièrement, on entame le principe d' Aristoteles à partir des conceptes de Arché, ousá et hypokeimenon. En suite, on passe à la question du subjectum et aux conceptions de véritées éterneles en Descartes et celle de la cloture de la metaphysique produite par la critique de Leibiniz à cette conception. Finallement, on développe la manière par laquelle Lacan a pensé le sujet de l'inconscient à partir de la place que la tradition metaphysique lui avait doné. L'invention freudienne suppose la metaphysique du sujet (ou plutôt, suppose sa supposition) et cette supposition nous fait repenser le sens de sa praxis.

Mots-clés: ousía; hypokeimenon; subjectum; cloture de la métaphysique; fermeture de l'inconscient; interprétation; transfert.

Desde Aristóteles a Descartes y Leibniz, y de ahí a Lacan. El presente texto quiere proponer un camino desde la filosofía al psicoanálisis, que se abre a partir de un problema: el de la suposición del sujeto. A partir de la entidad aristotélica, como presencia supuesta más allá del accidente, a la divinidad matemática cartesianoleibniziana, como supuesto para el sujeto pensante, se expone un mismo régimen de presencia y representación entre el principio y el sujeto, o como afirmará Heidegger, entre lo fundado y el fundamento. Entre ambos, se ha constituido una unidad, que es, al mismo tiempo, el final de la filosofía y su clausura como metafísica, constituida como onto-teo-logía. A partir de este régimen distributivo, se ha inaugurado una época que no cesa de ser la nuestra: la época de la subjetividad y de la "imagen del mundo" (Heidegger, 1996). Este acontecimiento, pesquisado desde la filosofía, no podría serle "interno", ya que de la manera en que ella lo ha propuesto -como un problema de época, pero que tiene la misma edad que la filosofía- no podría dejar de traer interrogantes a las prácticas para las cuales permanece insistentemente la cuestión del sujeto. Este último es el caso del psicoanálisis, a partir de Lacan, desde el momento en que ubica en primer plano la pregunta por el sujeto, para dar cuenta de la dinámica del inconsciente tal como la pensara Freud. Mantenerlo en el ámbito de la pregunta, permitirá a Lacan sostener que el inconsciente, como un corte entre el sujeto cartesiano -como presupuesto del inconsciente- y el lugar de la verdad- exigido por la dimensión de la palabrasólo se abre cuando ya se ha cerrado.

Esta concepción, que hace del inconsciente una pulsación temporal, se condice con el propósito explícito de Lacan, de no producir un sujeto específico para el campo freudiano y la práctica del psicoanálisis, sino que interrogarlo al interior de la tradición que lo produjo: considerándolo, a partir de su determinación inconsciente, como irreductible a la certeza conclusiva del cogito, expuesto a la cuestión del decir y de la alteridad del sentido. El sujeto, tal como lo entiende Lacan, se encuentra desprovisto de toda reflexividad, incapaz de desdoblarse en su relación a la verdad, incapaz incluso de saber que sabe. De esta manera, Lacan pretende brindar una nueva luz al sujeto, tal como Aristóteles lo entregó al decurso de la historia de la metafísica (Le Gaufey, 2010, pp. 47-48). Esto explicaría la gran importancia que tuvo para Lacan el término subversión, con el que no dejo de presentar el descubrimiento freudiano. Pero para comprender dicha importancia, ese término habrá que oponerlo, como veremos, al de sustancia. Porque la subversión freudiana retoma la separación entre sujeto y sustancia que ha constituido a la metafísica, interrogando lo que hay en el lugar de la sustancia.

La doble operación de Lacan sobre el sujeto de la metafísica -sostenido en las garantías de principio de la certeza y del sentido-es lo que soporta en la praxis, la relación entre interpretación y transferencia, y lo que le entrega al descubrimiento freudiano la especificidad del lugar que le corresponde. La subversión freudiana, se dirige al lugar que en la tradición metafísica le corresponde a la sustancia, porque el inconsciente implica que la suposición no alcanza nunca a subjetivarse como tal, a presuponerse a sí misma. Por esta razón, la pregunta por el sujeto del inconsciente, fundamental para el psicoanálisis, debe encontrar, en una cierta manera de interrogación filosófica, su examen y su esclarecimiento. Lo que sigue a continuación, recién es el comienzo de un derrotero abierto por la tradición filosófica -ahí donde busca convertirse en unidad-y en el que el psicoanálisis deberá exponer sus fundamentos, hablando de sí con la filosofía. 


\section{Aristóteles: Arché, Ousía e Hypokeímenon. Más allá de la Dialéctica}

En el libro V de la Metafisica (1013a), Aristóteles define las diversas acepciones de la palabra Arché o principio para luego encontrar en la serie lo que estas tienen en común. Este rasgo común corresponde a la evidencia de una esencia compartida, a la existencia de una naturaleza común en la serie de acepciones y no al hallazgo de una homonimia extraída de ella. Por esta razón es que los principios y las causas supremas que busca la ontología en su proyecto de ser la ciencia de lo que es en tanto que es con carácter universal, deberán comportar una naturaleza por sí mismos ya que comprenden al ser, en su lazo con el logos, como venida a la presencia de lo que permanece independiente de sus accidentes, volviéndose así inteligible y habilitando además lo predicable, en tanto que permanente fundamento de la enunciación sobre lo mismo. Es decir, si la expresión algo que es comporta múltiples sentidos, lo hace únicamente en relación con una sola cosa y una sola naturaleza desde la cual eso que es se dice. De este modo la entidad (ousía) se constituye en el sentido fundamental del ser y la categoría primera (Metafísica, VII, 1028a) porque de los múltiples sentidos que adquiere "ser" en el análisis de las categorías, el primero de todos es el que corresponde a la entidad porque expresa el "qué-es" de cada cosa. La expresión "algo que es" se dice en múltiples sentidos: por una parte significa el "qué es" como algo determinado, y por otra significa la cualidad, la cantidad o cualquier otro tipo de cosas que se predican de ese modo. Si "lo que es" se dice en esta multiplicidad se "hace evidente" para Aristóteles que lo primero es el "qué-es" o la entidad y las demás formas son "cosas que son" ya que las cantidades, cualidades o afecciones serán siempre determinaciones de la entidad. En todos los casos, la multiplicidad de sentidos remite a un único principio, porque en todos ellos la ciencia se ocupa fundamentalmente de lo primero (Metafísica, IV, 1003b). Por lo anterior es que el accidente o afección carece de autonomía ontológica, porque sólo puede darse en la entidad. De esto la pregunta de Aristóteles sobre si las acciones -por ejemplo pasear, estar sentado, sanarson algo que es o algo que no es, si pertenecen o no al ser primero o son meramente accidentes. Porque si el accidente es incapaz de existir de forma separada de la entidad entre las cosas que son debe contarse siempre el que pasea, el que está sentado o el que sana. Y si el accidente parece ser sin serlo es porque comporta un sujeto determinado, comporta la entidad individual que se hace patente en la forma de expresar los accidentes -"el" que se pasea, "el" que sana- por lo tanto lo que se pone de manifiesto y que saca al accidente de su indeterminación es que hay algo ahí en el accidente y que comporta el accidente. Así, la entidad se convierte en aquello que primeramente es pero que no es como tal bajo ningún aspecto sino que es simplemente, individualmente; la entidad es en definitiva "lo que no se predica de un sujeto, sino que lo demás se predica de ello" (Metafísica, VII, 1029a).

En Aristóteles, el fundamento se articula en la identificación de dos estructuras: una, que es una estructura de clasificación y presuposición lingüística, y otra, que puede caracterizarse como una estructura metafísica del conocimiento. A partir de esta articulación, se enmarca el concepto de ousía: primariamente, en la teoría de las categorías, en función de los juicios predicativos, y luego, en la distinción de dos tipos de expresiones -ya que no hay que olvidar que lo que es se propone como expresión: los juicios o proposiciones y las expresiones que no son tales (Categorías, II, 1a 15), siendo las proposiciones los elementos constitutivo con que se forman los juicios. Pero como el cuadro clasificatorio de las categorías comporta exclusivamente palabras que tienen función significativa o designativa, es necesario considerarlo, además de una clasificación de términos o locuciones simples, como una clasificación de los distintos tipos de realidad, de las cosas designadas por medio de las palabras clasificadas. Así, todo tipo de afirmación sobre las cosas, dentro de todas las posibilidades de afirmar algo sobre la realidad, la primaria (prôton) es la que se adecúa respecto al esquema lingüístico “¿qué es esto?”. A partir de ahí, todas las respuestas tendrán una estructura idéntica, ya que serán siempre nombres que signifiquen dentro de la categoría de entidad. Siempre deberá contestarse a la pregunta primera de la siguiente manera: "(esto es) un hombre o un dios" (Metafísica, 1028a15-18). De esta forma, es la entidad el sujeto o sustrato (hypokeimenon) entendido tanto como sujeto físico -porque ningún accidente puede darse ni tiene existencia por separado de la entidad- y como sujeto lógico de predicación - porque la afección no se dice sin la entidad. Pero la expresión algo que es, al decirse mediante una multiplicidad de sentidos, abre al verbo ser a la polisemia y expone un impasse para la constitución de una ciencia unitaria de lo que es (Aubenque, 1974). Es decir, si lo que es y lo uno son lo mismo y una misma naturaleza, se debe a que para Aristóteles, el ser que toma el nombre indeterminadamente como individualidad o entidad, el Logos lo expone como pluralidad (Agamben, 2007). Por ello que la pregunta por el fundamento -sobre el ser como Arché - toma en Aristóteles la siguiente forma: ¿por qué, mediante qué, algo pertenece a algo o es dicho de algo? El fundamento siempre se investiga del siguiente modo: ¿por qué algo pertenece [está debajo como principio] a algo? preguntar, en cambio, por qué una cosa es ella misma es no preguntar nada" (Metafísica, 1041a). Se corrobora una vez más que en todas las acepciones de primero o de principio, en todos los sentidos en que es posible decirlo, para todos ellos la entidad es primera, respecto a la noción, al tiempo $\mathrm{y}$ al conocimiento. El hecho y la existencia del hecho es 
lo primero que debe estar claro, siendo esa la única tarea del pensamiento, porque ninguna de las cosas que luego se predican, puede existir de forma separada como puede la entidad. Por lo tanto, solamente se conoce cuando se sabe qué es cada cosa y no por los accidentes mediante los cuales se presenta. La entidad es primera que la noción, ya que en la noción de cada una de las cualidades se incluye siempre a la entidad. La aporía de la pregunta por "lo que es" Aristóteles la resuelve identificándola con la pregunta ¿qué es la entidad?: "la cuestión que se está indagando desde antiguo y ahora y siempre, y que siempre resulta aporética, qué es "lo que es" viene a identificarse con ésta ¿qué es la entidad?" (Metafísica, VII, 1028b).

Pero ¿de qué manera se logra dicha identificación, cómo se la lleva a cabo? Del mismo modo que el movimiento supone un motor inmóvil y la denominación supone una premisa no deducida, la predicación por su parte supone la existencia de un sujeto -algo- que no sería atributo para que sea posible un discurso definitivo sobre algo. Mas esta última denominación para la entidad resultaría insuficiente como tal para solucionar el impasse arriba destacado y abre una cuestión que le es necesario formular de manera precisa a Aristóteles para sostener la ontología como ciencia fundamentalmente de lo primero. Abandonar la denominación de ousía de un modo simple en la de sustrato o sujeto llevaría rápidamente a considerar a la ousía como materia concluyendo de esta manera que la única entidad real y por tanto primera es la materia, ahora sustrato último de todas las determinaciones posibles, como sujeto último de toda predicación, transformándose de esta manera a las entidades primeras o individuos en simples accidentes. La materia convertida así en entidad conduciría a que indefectiblemente se nos escape todo sustrato y todo presupuesto porque

\footnotetext{
"las acciones, afecciones y potencias de los cuerpos, y la longitud, la anchura y la profundidad son, por su parte, tipos de cantidad, pero no entidades (la cantidad no es, desde luego, entidad): entidad es, más bien, aquello en que primeramente se dan estas cosas. Ahora bien, si se abstraen la longitud, la anchura y la profundidad, no vemos que quede nada, excepto lo limitado por ellas, si es que es algo. De modo que quienes adopten este punto de vista la materia les ha de parecer necesariamente la única entidad" (Metafísica, VII, 1029a10-20).
}

La indeterminación propia de la materia impide convertirla en el sujeto esencial de discurso alguno ya que la definición de lenguaje como "decir algo sobre algo" requiere de la presuposición del "algo" acerca de lo cual el discurso hace referencia, necesita la existencia ya ahí de aquello sobre lo cual habla, pero al mismo tiempo sin que eso habilite a su vez una conclusión monista respecto de la unidad; la composición que determina la materia y habilita la pregunta por el ser no soporta la mezcla sin separación. El accidente comporta una pura existencia nominal que lo aísla del sujeto porque el nombre es asimilable al sujeto pero no a la definición del atributo; el accidente sólo existe durante el discurso predicativo y cuando cesa el discurso el atributo vuelve al no ser (Aubenque, 1974). La verdad en la que cada ente se manifiesta debe encontrarse por esta razón separada de él y por ello supuesta como fundamento al discurso, al hecho de que algo se predica de algo; pero ese algo no puede ser formulado sino sólo proferido por el discurso (Heidegger, 2006).

El discurso, el Logos, se vuelve para Aristóteles mediación obligada para alcanzar el ser y ninguna ontología podría hacer abstracción de él al mismo tiempo que no podría quedarse solamente con él si es que quiere que el discurso juegue un papel expresivo o de transmisión: no solamente hablar sino que hablar de algo, no sólo nombrar sino que además manifestar eso de lo que se habla (Aubenque, 1974). Para Aristóteles por tanto es imposible poner en cuestión la existencia de ese referente último y que la entidad no se ubique allí, porque el fondo de todo discurso y desde el cual este se impulsa debe estar determinado y no ser algo indeterminado como la materia. La palabra entonces sólo será como tal palabra cuando el sonido señale a una cosa, cuando el opinar sea puesto ante algo que permita al opinar detenerse y delimitarse por ser esa cosa independiente de la expresión. A la entidad entonces le corresponde al mismo tiempo ser algo separado y algo determinado (tóde ti) por lo que sobre ella no cabe el error del mismo modo que del pensamiento no cabe decir si es verdadero o falso. La verdad y el error se dan solamente en el enlace de conceptos, teniendo lugar en la composición que se constituye como unidad. Aquello que se dice ser verdadero no es causa de que el hecho exista, sino al contrario: que el hecho se manifiesta como causa de que el enunciado (ho lógos) sea verdadero; pues el enunciado se dice verdadero o falso porque el hecho (tò prâgma) existe o no existe (Del alma, 430b).

Lo develado aquí, en definitiva, es que lo puesto primero requiere a su vez de la presuposición de su constitución. Si la ontología se ocupa de lo primero, de aquello de lo que las demás cosas dependen y si esto es la entidad, hay que encontrarse en posesión de los principios no hipotéticos que permiten que la entidad sea tal. Este principio debe hallarse separado y supuesto como fundamento porque lo que está dado de antemano no puede haber sido hecho si quiere ser principio y causa de lo que es en cada caso, si no se quiere que la entidad se pierda en el mar de los accidentes y su contingencia. El principio no puede ni hipotetizarse ni alcanzarse por la vía del conocimiento porque al mismo tiempo que se lo supone posible de conocer se lo considera como ya conocido. El principio se convierte así en parte de los bienes del filosofo, ya que aun cuando a él le corresponde la labor de investigar acerca de los principios de los razonamientos, 
al mismo tiempo "deberá hallarse ya en posesión de lo principios y las causas de las entidades" (Metafísica, IV, 1003b) si no quiere mezclarse él también con aquellos que "por ignorancia piden que sea demostrado el principio" (Metafísica, IV, 1006a). El principio de no contradicción es el que puede ser caracterizado como el más fuerte y excelso de los principios por cumplir rigurosamente con las características del axioma: ser universal y no hipotético. Sobre este principio es imposible el error en la medida que participa del intelecto impasible, sin mezcla e inmemorable porque una vez separado del otro intelecto, este último susceptible de corrupción, permanece en su ser inmortal y eterno (Del alma, 430a). Es imposible que un individuo, sin importar quién sea, crea que lo mismo es y no es, que lo mismo se dé y no se dé, a la vez, en el mismo sentido y en el mismo individuo. Pero esto es imposible también y al mismo tiempo de ser demostrado, porque "no puede haber demostración de todas las cosas": esta afirmación, al modo de una máxima, detiene un proceso que de lo contrario se extendería al infinito, volviendo indemostrable el proceso mismo de demostración. Así hay al mismo tiempo una suposición indemostrable por ser anterior y permanecer más allá de toda demostración, ya que es una afirmación con significado; y una demostración imposible mediante una proposición, porque implicaría que mediante un intelecto se explique otro, diferente y sin mezcla con él. Hay algo, que en este doble movimiento permanece idéntico siempre y en todos los casos, algo que queda retenido en sí mismo y que funcionará como punto de ordenamiento para todo el que tome la palabra y se dirige a otro mediante un discurso que tenga significado para sí mismo y para el otro a quien este se dirige. Queda demostrada de esta forma la fuerza del principio para Aristóteles, ya que aquel que quisiera destruir el lenguaje significativo, en su esfuerzo, lo mantiene, permitiendo que haya una verdad de principio (Metafísica, IV, 1006b), aun cuando esta quedé más allá de la dialéctica: que las palabras ser y no ser signifiquen algo determinado realmente y no nada, que el lenguaje predique sobre el ser y no se confundan los nombres y los seres, que exista, en definitiva, un fundamento que sostenga tanto al conocimiento como al Logos.

\section{Descartes y la Crítica de Leibniz: Las Verdades Eternas, el Subjectum y la Clausura de la Metafísica}

Es a los principios, entonces, hacia donde deberá dirigirse de ahora en más el entendimiento, porque a ellos se encuentra ligado originariamente. Esta orientación del entendimiento, resume la búsqueda cartesiana de un fundamento infinito para el ser finito. Pero para que ello sea posible, los principios deben cumplir dos condiciones: la primera, es la claridad y evidencia, para que el espíritu cognoscente no comprometa la verdad cuando se dedique a ellos; y la segunda, es que de los principios dependerá todo conocimiento de las cosas, al punto de que puedan ser conocidos aun sin éstas, pero no éstas sin aquéllos, estableciendo una dependencia no recíproca, que impide que exista, en la cadena de las deducciones, algo que no sea manifiesto. La verdad, sostén de los principios, puede corresponderse con el pensamiento, sólo bajo el modo de la unidad, porque sólo de esta forma es posible el conocimiento. Bajo esta exigencia de unidad, es que aparece esa figura del pensamiento que Pascal llamó el "Dios de los filósofos y de los sabios", el que es no es más el de la revelación, el de "Abraham, de Isaac y de Jacob". El entendimiento, para Descartes, se ocupará de una diversidad inmensa de cuestiones, clasificando y diferenciando tantos objetos como sea capaz de concebir en una disposición ordenada de identidades y diferencias, pero nadie realmente, sino Dios, "es perfectamente sabio", porque nadie más que él tiene "el entero conocimiento de la verdad de todas las cosas"; se podrá afirmar que los hombres tienen en mayor o menor grado sabiduría, en razón de que tienen más o menos conocimiento de las verdades más importantes (Descartes, 1987). La diversidad genérica de la razón encuentra de esta manera su asidero y su ser en la unidad eterna de la sabiduría divina, siempre que el Dios de la revelación y el misterio de su Trinidad dejen de ser problemas -como lo fueron para la escolástica- de la incumbencia de la filosofía. Él, deberá responder de ahora en más, no ya a las plegarias que llaman a su revelación, sino que a las exigencias de la racionalidad. Porque si para Descartes hay un error en la historia de la filosofía, es que esta ha decidido fundarse en la suposición de algo no conocido a la perfección: "cuando tenemos malos principios, mientras más los cultivamos y nos aplicamos con más cuidado a sacar de ellos diversas consecuencias, pensando que de este modo se filosofa bien, más nos alejamos del conocimiento de la verdad y de la sabiduría. De ahí se debe concluir que los que menos aprendieron de todo aquello llamado hasta ahora filosofía, son los más capaces de aprender aquella que es verdadera" (Descartes, 1987, p. 12). La unidad de Dios frente a la multiplicidad de los conocimientos se relaciona con la exactitud de la verdad matemática convertida en vehículo para aprender la que es la verdadera filosofía. Porque la verdad matemática y lógica al no comportar un carácter aproximativo impide la indeterminación; son verdades que se saben exactamente independiente del espíritu que haga uso de ellas. Las matemáticas son el acercamiento posible entre Dios y el espíritu que conoce, porque los axiomas matemáticos se encuentran en el mismo nivel que la divinidad asegurando la distancia en la relación a Dios. Es decir, el entendimiento será movimiento errabundo y equívoco pero sobre un fondo de unidad ya que la matemática y la geometría son la eliminación de la equivocidad dada por los sentidos al mismo tiempo que la seguridad que resguarda el saber de la 
falsificación en su carácter de inagotable cuestionamiento a sí mismo. La matemática se transforma en la forma de dominar la doctrina natural medieval y antigua de la analogía, es el corte con ésta y el nuevo comienzo de la filosofía (Marion, 2009, p. 13).

Si la sustancia infinita, independiente y supremamente poderosa que es Dios para Descartes (Descartes, 2012) es el autor de las cosas y de las verdades es porque de él depende, como modelo ontológico, que éstas sean algo en vez de nada. Los entes creados -ens creatum- requieren de la concurrencia divina para ser lo que son, pero Dios como increado - ens increatum- y únicamente sustancia no tiene necesidad de nada más que de sí mismo para existir. Diferencia que se vuelve pensable porque el atributo de Dios como sustancia Descartes se sabe pero no se comprende: se puede saber perfectamente que Dios es infinito aun cuando el entendimiento sea finito. El equilibrio precario de las analogías es abandonado aquí por la seguridad que entrega la diferencia entre comprensión y saber, inaugural en toda definición de la filosofía tal como la entiende Descartes: los matices de la relación a Dios no se encuentran en la naturaleza al modo de signaturas sino que en la capacidad del espíritu que se encamina en dirección de Dios (Le Gaufey, 2012). Hay por tanto lo que puedo saber sin jamás comprenderlo ya que el infinito de la naturaleza de Dios comporta toda tentativa de comprensión por parte del intelecto, haciendo que una afirmación como yo sé que no lo comprendo sea parte del patrimonio de la certezas del entendimiento y le sirva de guía a ego para conducirse en la vida dándose un mundo. El Dios Uno y Autor de las verdades eternas permite que la precariedad y fragilidad del conocimiento se vuelvan su soporte más cierto: "Porque aun cuando exista en mí la idea de substancia por el mismo hecho de que soy substancia, no existiría la idea de substancia infinita, siendo yo finito, si no procediese de alguna substancia infinita en realidad" (Descartes, 2012, p. 24). La substancia divina, tan incomprensible como infinita, hace que el entendimiento sólo pueda ser informado de la existencia de la idea de Dios porque ésta no pudo provenir desde él mismo por ser substancia finita; la idea de Dios es una idea que no pudo haberse aprendido nunca, es una idea primordial e innata al pensamiento. Un saber que no requiere de comprensión es la mayor muestra de un Dios infinito como figura indispensable de la certeza del cogito y el mundo que este inaugura, por lo que el alejamiento y la distancia sin límites de Dios es fundamental porque sostiene la subsistencia del pensamiento. Al respecto es como Descartes, en Los Principios de la Filosofía, afirma que ha de ser pues evidente que quien conoce algo más perfecto de lo que él es, no se ha dado él mismo el ser, ya que "de igual modo se habría atribuido todas las perfecciones de las que hubiera tenido conocimiento; en consecuencia, sólo subsistiría en virtud de aquel que, en efecto, posee todas estas perfecciones, es decir, de Dios" (Descartes, 1987, p.
34). Dios responderá a las exigencias de la racionalidad para ser mantenido, paradójicamente, más lejos de estas ya que solamente así podrá fundarlas como tales. Aquí se encuentra el método que habilita al pensamiento a alcanzar más allá de la prueba lo que la prueba misma buscaba demostrar. Porque se identifica desde el comienzo el camino de las equivalencias entre el nombre y el referente, entre la representación y la cosa y permite además al pensamiento “separarse de la separación” (Marion, 1977/1999, p. 25) del infinito divino. El rigor de la demostración sólo podrá llegar, en su indefinición, hasta el último concepto será también el momento que marca la distancia infranqueable del retiro de Dios:

aunque mi conocimiento se engrandezca siempre más y más, nunca, no obstante, será infinito en acto, puesto que nunca llegará a un extremo tal en que ya no sea capaz de un incremento mayor todavía. Por el contrario, juzgo a Dios infinito en acto de tal modo que nada puede añadirse a su perfección. (Descartes, 2012, p. 25)

Que el saber logrado en su verdad sea incomprensible por tener un valor representativo nulo -en tanto participa de la comprensión como su punto de fuga- hace que el alejamiento de Dios no se rebaje a lo arbitrario del capricho humano paras así convertirse en una negatividad fundamental del orden del saber: la omnipotencia divina funciona como fundamento óntico y epistemológico al excluirse del orden y la medida de la episteme, en la exacta medida que la verdades necesarias no son queridas necesariamente por Dios. Omnipotencia e incompresibilidad hacen al nombre de Dios sólo si esto deja de lado su querer o su voluntad, porque "en Dios es la misma cosa querer, entender y crear sin que uno preceda al otro, ne quidem ratione (ni siquiera lógicamente)" (Le Gaufey, 2012, p. 33). Esta misma cosa que es en Dios querer, entender y crear permite, finalmente, que aunque una idea pueda proceder de otra, no se da, sin embargo, una sucesión de su encadenamiento hasta el infinito sino que llega a una primera idea cuya causa es equivalente a un original, es decir, a una causa que es causa de su propia idea.

La mathesis universalis, como intento de fundar un saber completo, requiere de axiomas que sean tanto absolutamente primeros en sí y por sí evidentes y absolutamente ciertos, estableciéndose de antemano respecto a la totalidad de los entes. El ente se determina entonces a partir de la proposición y la proposición por su simpleza mantiene un contacto directo con lo que es tal como es. De esta manera la proposición se vuelve algo presente a sí mismo. Por lo tanto, nada puede haber anterior a la proposición fundamental y absoluta de la matemática, porque eso haría de la proposición algo arbitrario; la proposición debe ser puesta entonces sobre su fundamento. El principio, entonces, para ser como tal principio, deberá 
ser principio absoluto (Heidegger, 2009) y así resituar el principio de todo poner para que aquello que subyace al decir entendido como subjectum/hypokeimenon no sea meramente asumido desde un ámbito cualquiera. Sólo así el subjectum se vuelve fundamento absoluto. En relación a esto es que la duda sostiene la certeza del pensamiento, porque buscando lo matemático como fundamento absoluto se obtiene como resultado que para todo saber exista un sustento que le corresponda. Porque con esto, lo único dado es la proposición en general y en tanto que tal, el poner de la proposición es un pensar enunciativo. Así es como el pensar solamente se tiene a sí mismo como aquello que puede ser puesto, por lo que sólo donde el pensamiento se piensa a sí mismo hay matemática y solamente donde el pensamiento se piensa a si mismo hay como tal pensamiento.

El pensar y el poner, el enunciado y la enunciación, se remiten uno a otro para concluir que sea lo que sea sobre lo que se enuncie, este enunciar y pensar será siempre un yo pienso. Así es como el soy se transforma en la certeza suprema que yace de forma inmediata en la proposición. Lo que es, por tanto, se determina desde el yo pienso como certeza de poner las bases de pensar. Pero esto no convierte al cogito ergo sum en la conclusión de un silogismo -ergoaun si así lo parece, porque el sum no es una consecuencia del pensar sino que el fundamento del pensar: se da, en un mismo movimiento, a sí misma como proposición y lo que de antemano está dado en ella (Heidegger, 2000). El yo es de esta manera el subjectum del principio absolutamente primero, es eso que yace en el fundamento -hypokeimenon, subjectum- es el poner absoluto y por ello Descartes "se refiere al yo preferentemente como sujeto" (Heidegger, 2009, pp. 134-135). De ahora en más, el yo es lo auténticamente dado de antemano para el representar, pero lo que no depende desde ningún punto de vista del yo ni de la subjetividad de la duda, sino que de su lazo con el dominio de lo axiomático y lo matemático, porque ese dominio no es algo subjetivo al modo de una propiedad casual del hombre sino que depende de la suposición de Dios. Es lo dado de antemano sobre la que se sostiene la reflexión cartesiana en torno del tiempo anterior que pone en juego el cogito. Porque si a partir de que ahora existimos

no se sigue necesariamente que seamos un momento después, si alguna causa, es decir, la misma que nos ha producido, no continúa produciéndonos, es decir, si no nos conserva (...) solamente si existe en nosotros una fuerza en virtud de la cual podamos subsistir o bien conservarnos un sólo momento y que quien tiene tanto poder que nos hace subsistir con independencia de él (...) por lo que quien conserva la subsistencia debe conservarse a sí mismo, porque no tiene necesidad de ser conservado por alguien; esto es, que es Dios. (Descartes, 1987, p. 35)

Entonces desde el yo las demás cosas se determinan como tales y adquieren su ser a partir de un funcionamiento conjunto del principio supremo y su sujeto. Si para Aristóteles era el Logos o el enunciado, el hilo conductor de la determinación de las categorías como determinación de lo que es, para Descartes es la subjetividad del sujeto la que ocupa ese lugar, ya que la razón, como yo pienso, se ubica como principio supremo.

Pero la concepción de las verdades eternas no fue recibida sin objeciones por parte de los cartesianos. Entre ellos, fue Leibniz el que manifestó más expresamente su desacuerdo y su crítica se volvió sumamente ilustrativa de la complejidad que estas presentaban. Porque más que lograr rebatirla, la crítica de Leibniz la profundizó y solventó mediante la noción de sustancia individual o mónada. Pero no sólo porque este concepto también responde a la implicancias metafísicas de lo axiomático y lo matemático, sino que además porque superando a Descartes donde este se habría detenido en el esclarecimiento del cogito, Leibniz permanece en la misma encrucijada que Descartes, y queriendo relevarlo clausuraría la metafísica: de esta forma la crítica se vuelve un acabamiento, donde la pretendida "superación" es al mismo tiempo una resolución. Por esto es que si la teología metafísica cartesiana, como ha afirmado Jean-Luc Marion, "permanece en vela", es porque sus beneficiarios o sus portadores, han permanecido anónimos (Marion, 2009).

Para Leibniz, la sustancia individual y finita que es el sujeto es aquello a lo que se le atribuyen predicados, al mismo tiempo que este sujeto no es atribuido a ningún otro predicado más que a aquellos que le corresponden. Esta sustancia individual es un versión disminuida de la perfección de la sustancia infinita, por lo que la sustancia finita puede reflejar según diversos grados de adecuación a la sustancia infinita. Pero aunque finita, esta sustancia envuelve lo infinito ya que involucra infinitos modos de componerse y de fundar relaciones con infinitas sustancias diferentes. Toda predicación por tanto tiene fundamento en la naturaleza de las cosas por lo que cuando una proposición no es idéntica, cuando el predicado no está comprendido de forma expresa en el sujeto

es preciso que lo esté in-esse (estar en, inherir) afirmando que el predicado está en el sujeto. Así es pues es preciso que el término sujeto encierre siempre al de predicado, de modo que quien entienda perfectamente la noción de sujeto juzgue también que el predicado le pertenece. (Leibniz, 2003, p. 332)

Todo juicio verdadero predica sobre un sujeto aun cuando ese predicado no se encuentre actualmente en el sujeto sino que virtualmente, es decir, que el predicado le es inherente al sujeto. Por lo tanto, la naturaleza de la sustancia individual como ser completo es tener una noción acabada de ella para comprenderla y permitir la deducción de todos 
sus predicados aun cuando puedan requerirse infinitos pasos intermedios entre uno y otro, tantos que el hombre no llegue a darlos todos. En esto Leibniz parece estrictamente aristotélico ya que diferencia entre la naturaleza del sujeto y los accidentes, entre la completitud y la incompletud, pero con el agregado de una inherencia virtual que supone una presencia por venir que se asegura en la figura de Dios. De la misma manera que en Descartes, en el momento de adecuación entre el sujeto y sus atributos surge para Leibniz la necesidad del Dios matemático e infinito, fundamento de la inherencia del predicado, haciendo que los fundamentos no participen del conocimiento sino que del saber de los principios de la lógica y de la ontología en su determinación universal. De esta manera, por ejemplo, desde siempre hubieron vestigios de todo lo sucedido y de todo lo que sucederá en el alma de Alejando Magno, ya que su calidad de rey no está completamente determinada por un individuo pero se presta para la expresión de todos ellos -que vencerá a Darío y a Poro, saber si la causa de su muerte fue natural o por envenenamiento, etc. Todos estos atributos únicamente a Dios le corresponde reconocerlos (Leibniz, 2003). Pero que la materia pueda recibir sucesivamente todas las formas o que lleguen a existir alguna vez todos los posibles no responde a ninguna fatalidad a la que sería inútil resistir. Solamente podría pensarse así la reflexión entre las sustancias finita e infinita cuando se suprime el carácter hipotético de la causa divina o de los fundamentos de la propia existencia: "es verdad que todo lo que ha de ocurrir, efectivamente ocurrirá, pero no necesariamente, con necesidad absoluta, es decir, obres o no obres" (Leibniz, 2003, p. 138). El efecto solamente se vuelve necesario a partir de la hipótesis de la causa, por lo que es el acto el que demuestra lo que ha sido predestinado desde la eternidad. Porque antes de que ocurra, no es posible saber $-\mathrm{y}$ si es posible, tal vez nunca sea posible saberlo del todo- si la cifra del destino nos era favorable o adversa. Es preciso, entonces, que la razón suficiente, como aquella que no tiene necesidad de otra razón, se encuentre fuera de la serie de las contingencias individuales y se anude a una sustancia que sea, esta, la causa de esa misma serie. Esta sustancia es un ser necesario, al igual que en Descartes, que lleva en sí mismo la razón de su existencia, porque sin él, no habría una razón suficiente donde puedan delimitarse los juicios.

Tal como en Descartes, para Leibniz la perfección del ente divino equivale a su autosuficiencia y autarquía, al estar alejada de todo lo que es. Pero lo que Leibniz explicita tal vez de un modo más evidente que Descartes es el juego recíproco entre el fundamento y lo fundado, el reenvío constante entre dos modos de presencia que se quieren mantener separados y que caracteriza a la clausura de la metafísica como onto-teo-logía:

La constitución onto-teo-lógica de la metafísica procede del predominio de la diferencia que mantiene separados y correlacionados mutuamente al ser en tanto que fundamento, y a lo ente en su calidad de fundadofundamentador, proceso que es llevado a cabo por la resolución. (Heidegger, 2013, p. 30)

De esta manera, Dios como garante y fundante, aparece tanto para Leibniz como para Descartes, como límite a todo lo pensable y lo enunciable, surgiendo en el lugar de todo llegar a ser y de todo dejar de ser; como presencia constante que asegura, la presencia de Dios es solamente posible y no empíricamente comprobable por ser nada de lo que es.

\section{Lacan: Apertura y Cierre del Inconsciente o la Estructura de la Equivocación como Causa del Sujeto}

Para el pensamiento metafísico, Dios funciona como la sustancia eterna y atemporal que, más allá del ente, los ordena y determina. El Dios causa sui sería el único que permite a cada ente ser lo que es, porque funda a cada uno de ellos ejemplarmente, como modelo ontológico, en la misma medida en que el ser se despliega en él como presencia plena. Pero si el ser no fuera ya y de antemano presencia -como ousía o parusía-Dios no tendría sobre qué realizar su decisión fundadora. Solo así puede convertirse en fundamento que se funda a sí mismo, lo que hace que "el pensamiento de Descartes, que es el primero en pensar a Dios como causa sui a partir de su exuberancia de poder, halle en Leibniz su auténtico estatuto metafísico" (Marion, 1999, p. 27). Pero el pensamiento representativo, que se organiza a partir de la diferencia entre el ser y el ente, en el momento conclusivo en que busca retornar a sí y clausurarse gracias a ese prototipo ontológico, se abre y se desborda hacia un nada-de-presencia, hacia algo que no cesa de no presentarse y que lo funda. Una nada que se abre en el fundamento, que lo abre y expone. En ese lugar, el psicoanálisis buscaría decir algo, de sí mismo y de la filosofía en su constitución onto-teo-lógica, a partir del descubrimiento del inconsciente y de la praxis que con él se inaugura. Porque el inconsciente altera -por la originaria otredad del lenguaje y sus efectos sobre el sujeto- todo cumplimiento del sentido, separando la conjunción epocal entre sujeto y saber, interrogando la "doble lógica del abismo" de la metafísica: el encierro en sí, o la caída vertiginosa fuera de sí (Nancy, 2014, p. 57).

El inconsciente, afirmará Lacan, no se abre sino en la medida en que resulta que se cierra ¿Respondería esta formulación de lo inconsciente, y del sujeto que le es correlativo, al mismo cierre, a la misma clausura que acabamos de presentar? Y si así fuera ¿Por qué el inconsciente podría ser, al mismo tiempo que un nuevo epílogo de la metafísica, la apertura del cerrojo metafísico? ¿Cómo lo sería? Se trata con estas preguntas de perfilar la tópica de lo inconsciente en su relación con el lugar donde 
se reuniría la totalidad de la historia como fin de la filosofía, con el soporte de la metafísica devenida mundo (Heidegger, 2000). Porque el cierre del inconsciente es lo que da la clave del espacio que lo caracteriza, pero con la salvedad, primero que todo, de que es incorrecto concebirlo a partir de un adentro al modo de la extensión. El cierre del inconsciente, refiere más bien a una clausura de orden temporal de un lugar, el que por reducirse a una combinatoria topológica, se transforma en algo más necesario que medible o hallable, demostrando su núcleo de tiempo reversivo: retroacción del efecto de sentido, donde se encuentra la eficacia del discurso (Lacan, 2008b, p. 798). Ese lugar, del que su cierre da la clave, es impropio considerarlo como un dentro. Porque aun cuando se abre donde se piensa el pensamiento -ahi donde pienso... pensar-se transforma, por esa misma razón, en un lugar irreductible al punto o a lo puntual del momento enunciativo del cogito, cuando este busca trazar el círculo de retorno sobre sí para apropiarse de su ser de manera sintética. Se trata, entonces, de si ese círculo, estrechándose al modo de un lazo, se cierra sobre un espacio cuya existencia sería anterior a la incidencia de ese estrechamiento, o si opera sobre una superficie que sería más bien efecto de dicho cierre, para definir con esa misma operación, las estructuras que pueden, y las que no pueden, reducir o colmar el agujero que dibujaría la hipérbole de la duda. El camino de la (re)constitución por el pensamiento de la síncopa temporal que causa al sujeto -que lo ubica entre el sentido y la existencia- hace posible prefigurar la posibilidad de un tipo irreductible de falta - una falta que el discurso, en su método, no suple y que es constitutiva del sujeto que resultaría de ese gesto.

Desde Freud, cuestión que Descartes desconocía activamente por su concepción del sujeto como rechazo de todo saber anterior, sabemos que el sujeto piensa antes de alcanzar cualquier forma de certeza. Porque piensa ya $a h i$ donde no piensa pensar: con eso es con lo que debemos cargar y por ello "estamos tan embarazados" de un campo del cual no es posible sustraerse así como tampoco de la preguntas que este formula (Lacan, 1987, p. 44). Por esto es que no es posible obviar que tanto para Freud como para Lacan el inconsciente son pensamientos y es ese el sujeto de lo que desde el principio puede serle atribuido, es esa la primera respuesta posible a la pregunta por lo que es. Por lo que si fuera posible una ontología del inconsciente, o si el descubrimiento del inconsciente propone una cuestión ontológica, este debería ser su punto de partida ya que "eludir al cogito bajo el pretexto de su apariencia filosófica es simplemente dar prueba de inhibición (...) es también prohibirse el acceso a lo que puede llamarse el universo de Freud" (Lacan, 2008a, p. 483). Ahora bien, la complejidad de esta afirmación de Lacan, estriba en que el pensamiento se ha propuesto en su faz moderna como progreso, como movimiento de un discurso universal que se acumula tomando desde sí mismo el material de su propio avance, al haber cortado sus amarras con la tradición. El pensamiento retrocede sobre sí, se reconoce y se impulsa hacia delante mediante el expediente de la certeza, cumpliendo de esta forma una nueva etapa de su movimiento. Pero cuando se pone en cuestión la idea misma de progreso del pensamiento a partir de que este desconocería lo que lo ha causado ¿sobre qué regresaría ahora cuando se piensa a sí mismo? Habrá que poner en cuestión, entonces, toda pretensión de conocimiento junto con la idea de progreso cuando se aborda el inconsciente, porque no podemos saber de antemano si este tiene un ser propio, es decir, no podemos llamarlo simplemente "es eso" [das $E s]$ por lo que Freud lo denominó Es (Lacan, 2012). El inconsciente no acontece como presencia -aun si fuese ignota- sino que como latencia o pulsación entre apertura y cierre. Considerándolo de esta manera, el inconsciente no puede comprenderse ni como el producto de una inferencia, ni como la metáfora de una oscura profundidad, ni como la hipótesis de algo real y científicamente entendido. Su forma esencial es la discontinuidad, y su fenómeno, la vacilación del pensamiento. Apareciendo allí donde la conciencia pierde pie, el inconsciente se experimenta en su verdad en el lapsus, en el chiste y el acto fallido, ahí donde no se deja atrapar. En cuanto eso "aparece" en la conciencia, a partir de la marca de la equivocación, ya ha desaparecido como tal tras la marca, lo que hace que en el intento de apropiación del fenómeno por parte de la conciencia, ella misma se transforme en una huella evanescente, siempre segunda en el tiempo y siempre abierta al porvenir. Por esta razón es que para Freud la conciencia sólo adviene en remplazo de una huella mnémica, por lo que memoria y conciencia se excluyen (Freud, 2008a, p. 533). En esta sustracción de la presencia se funda la interpretación freudiana del inconsciente. En ella es donde encuentra su verdad. Pero esta sustracción, a pesar de las indicaciones de Freud, habría sido tomada como defensa, como escondite en una profundidad que debe ser explorada por el medio de la palabra. Si Freud promovía un análisis de las resistencias, lo hacía para que el psicoanalista tomara en consideración "todo lo que perturba la prosecución del trabajo analítico", lo que sólo debe ser considerado como una regla para él (Freud, 2008a, p. 511). Freud sólo consideraba a la resistencia y las defensas en su valor estratégico al interior de un análisis. Nunca en su valor "en sí,, para demostrar lo que se escondía o velaba en lo inconsciente. Este es el origen bajo y humilde de la verdad del inconsciente, que no comienza a partir del concepto ni descansa en la meta de la definición. El psicoanalista, advertía Freud en uno de sus últimos textos, debe rehusarse a definir el inconsciente, para poner en evidencia el grupo de fenómenos que lo llevan a postular su existencia. Freud resaltaba con ello la sutileza del acto fallido (Freud, 2008b), que demuestra una de las características más preciosas del inconsciente: ser una oportunidad siempre singular. Particular procedencia del inconsciente, que se evidencia, 
además, en el modo en que Freud lo interrogaba (Freud, 2008c): lo que aparece y desaparece de la conciencia, lo que acontece en la conciencia por su misma sustracción, entre su aparición y su desaparición ¿qué era eso que acontece en el transcurso de ese lapso? ¿dónde estaba eso antes y dónde queda eso después? Si todo acto inconsciente aparece bajo este aspecto de tropiezo, de falla y de fisura, es porque lo que se produce en esta hiancia-de un lugar anterior y de un tiempo anterior-alcanza de todas maneras a presentarse como un hallazgo para el sujeto, pero en el que es tomado por sorpresa, rebasado por lo que encuentra. El sujeto sólo puede caer en la cuenta de lo ya ocurrido y advenir allí donde eso estaba, pasando al campo del significado.

Es la estructura de la equivocación, en su lazo a la producción del saber, lo que debe ser expuesto para no equivocarnos... sobre la equivocación. Porque si para el psicoanálisis el acto nunca es tan bien logrado como cuando es fallido, esta definición no implica la reciproca sin el costo de la degradación del sujeto a su forma psicológica. Son los efectos de lenguaje -efectos de palabra en una estructura de lenguaje- todo lo que concierne al inconsciente, es eso que juega y gana a espaldas del sujeto, es eso lo que lo hace pasar al campo del significado, desde donde se lo llama al campo de la representación. El sujeto se ubica de esta manera no al nivel del Uno sino que al nivel del "un uno", al nivel de la cuenta. Porque el que cuenta debe contarse dentro de la cuenta transformándose así en una falta respecto a la realidad que conoce. Esto hace que todo intento de restitución de la historia, de concebir la historia como continuidad, produzca en su misma tentativa, la repetición de una relación que desde el origen es temporalmente discontinua, que es la repetición de la originaria inscripción de la historia el tiempo. Por esto, es que el inconsciente es algo que se dice, pero sin que el sujeto pueda representarse ni decirse a sí mismo allí donde acontece lo que causa ese decir, en definitiva, donde dice sin que sepa que dice. Pero esto quedaría irremediablemente en las sombras, cuando el sujeto es reducido a la presencia, mediante el yo pienso. Mediación de la sustancia pensante, que no cesa de implicar "todos los poderes de la reflexión en los que se confunden sujeto y conciencia" (Lacan, 2012, p. 221). Porque es en el momento de esa supuesta coincidencia captada por la reflexión, al modo de una clausura o cumplimiento, donde la experiencia psicoanalítica recién se encuentra con su comienzo. La praxis psicoanalítica demuestra que el sujeto del cogito, por encontrarse en el tiempo, cuando busca su propia fundación, revela su ser: no una presencia trascendente, sino que "el ser de una caída" (Lacan, 2012, p. 222). Considerando esto, es que Lacan propone escribir así la sentencia cartesiana: pienso: "entonces soy". Para de esa manera, leer en ella que "el pensamiento no funda el ser sino anudándose en la palabra, donde toda operación toca a la esencia del lenguaje" (Lacan, 2008b, p. 821). En el momento conclusivo de la ascesis cartesiana, que ha servido de base a toda la concepción moderna del sujeto, conciencia y sujeto son hechos coincidir, pero lo que esa coincidencia oculta es lo que esta tiene de equívoco: que ese momento privilegiado de la enunciación del cogito, capte exhaustivamente al sujeto; que el tiempo de la determinación sea absoluto respecto de lo que determina; que exista un instante de adecuación entre lo constituyente y lo constituido, entre lo determinante y lo determinado. Hay aquí una apariencia que debe conducir a su razón y en torno a la cual debe ordenarse la experiencia psicoanalítica y la pregunta por el inconsciente.

Ergo, entonces...no es para Lacan el instante de la adecuación, sino que el rasgo de la causa, que divide al sujeto entre el sentido y la existencia. Porque si el cogito promueve un pensamiento, es aquel que estaría ausente de todo yo soy. Cuestión que le permite concluir que no es el pensamiento el que se subordina al significante, sino que el sujeto del pensamiento, en la medida que la certeza del cogito se sostiene de su enunciación como punto de síntesis. Por ello es que para Lacan, Freud procedía de forma cartesiana en su obra inaugural La interpretación de los sueños, en la medida en que comienza por el fundamento del sujeto de la certeza, de aquello de lo que el sujeto puede estar seguro. La palabra utilizada por Freud allí es Gewissheit, certeza, porque lo que debe vencerse es una connotación presente en todo lo que toca al contenido de lo inconsciente y que ensucia el texto del sueño. El soñante afirma no estoy seguro, dudo. Lo que se vuelve manifiesto para Freud en esta declaración es que la duda es el apoyo de una certeza, y que con ella hay, en reserva, algo que preservar. Por lo tanto, la duda se transforma en una forma de resistencia (Lacan, 1987). Pero el nervio de esta cuestión propuesta por Freud no se encuentra en la existencia de un orden de indeterminación en la relación del sujeto a un saber que lo sobrepasa, ya que en esto se ha sostenido toda práctica interpretativa anterior al psicoanálisis, sin que haya existido la necesidad de especular sobre lo inconsciente. La cuestión consistiría, más bien, en que a partir del descubrimiento del inconsciente "pueda existir allí un decir que se diga sin que uno $[o n]$ sepa quién lo dice; he aquí a lo que el pensamiento se sustrae: es una resistencia ón-tica" (Lacan, 2012, pp. 354-355).

Lacan juega con el término uno $[o n]$, haciéndolo tanto un soporte del ser - como ente- como un soporte de la interpretación como omnitud, como sujeto supuesto al saber, en definitiva, el Dios despojado de su latencia por la teoría, pero brindándole al mismo tiempo su último refugio (teo-ría). ${ }^{1}$ Como el yo pienso se vuelve un punto

$1 \quad$ Para que el psicoanálisis pudiese existir, Freud debió abandonar todos los privilegios que le brindaba su "teoría de la seducción". En ella, se encuentran con suma claridad los efectos clínicos que trae defender la teoría: producir sugestivamente aquellos recuerdos que se quieren escuchar, siempre en nombre de los cantos de sirena de la teoría, 
de desvanecimiento y no el lugar de un saber cierto, surge el "deseo cartesiano" de un Otro que no engañe y que pueda garantizar con su existencia los fundamentos de la verdad. Un Otro que garantice en su propia razón objetiva los fundamentos necesarios para que lo que acaba de asegurarse -yo soy- pueda encontrar la dimensión de la verdad, avalando el saber de ego como totalidad ordenada. Será entonces la naturalización de esa figura la que se convierte en la resistencia misma del psicoanálisis -de su teoría y de su práctica, porque encubriéndola con el manto de la naturalidad se cubre él mismo del problema que le impone. Es decir: para ese saber, que solamente acontece en la equivocación ¿existía ya un sujeto, que lo haya sabido antes, y en el que la equivocación pueda enmendarse posteriormente? ¿Hay una continuidad de la historia para ese saber, una totalidad de ella? ¿El análisis, finalmente, conduce a una síntesis? El sujeto supuesto saber, determinado sólo por la inmediatez de la interpretación, se convertiría en una reserva óntica, que se sustraería, desde el inicio, al juego significante del inconsciente. Entendido de esa manera, la hiancia del sujeto volvería a cerrarse en el mismo momento en que se la encuentra, haciendo que el estrépito del traspié sólo sirva como sostén al mayor de los anhelos: el deseo de dormir, como instancia última del sueño (Lacan, 2012). Si el psicoanálisis se conformara con esta determinación del sujeto supuesto al saber, sostendría su operatoria a partir de lo tenue e indefinido de un sentimiento oceánico, fundamento de la religiosidad, saber eterno y anhelo de infinito, del que Freud declaró siempre sentirse tan ajeno. El psicoanalista no desea lo infinito. Dios es el único que posee un deseo infinito, un deseo sin marcas que lo particularicen, un deseo que no inscribe ninguna falta. La afirmación de Lacan de que el deseo está articulado aún

que prometían una "cura total de la neurosis" y una intelección total de la “etiología de la neurosis" (para comprender los pormenores y las versiones de este episodio fundacional, véase el insustituible libro de Mauro Vallejo (2014) La seducción freudiana (1895-1897). Un ensayo de genética textual). Pero que la teoría estuviera errada, no evitaba que en el relato de los supuestos seducidos, existiera una verdad. De la seducción en la infancia, Freud pasa a la noción de libido, la que sólo puede entenderse, si no se echa mano de ese sujeto ideal y único que es el sujeto teórico. La discusión que al respecto sostuvieran Freud y Jung sobre el distingo entre energías pulsionales, es ilustrativa de la postura freudiana. Freud la resume en el primer apartado de Introducción del narcisismo, oponiendo a la tranquilidad inmóvil y contemplativa del teórico -que exige una diferencia clara y distinta- la dinámica incierta a la que se enfrenta el clínico -dispuesto a abandonar todos sus conceptos, cuando se sumerge en lo nebuloso de la observación (Freud, 2012, pp.74-75) . Suponemos que Lacan tenía esto en consideración cuando, en la lección del 19 de mayo de 1955 del seminario El yo en la teoría de Freud... (Lacan, 2004) afirmaba que la experiencia freudiana se opone a toda perspectiva teórica, porque la libido implica que en ella hay algo imposible de objetivar, lo que revoluciona toda experiencia que el sujeto pueda tener de sí. si no es articulable apunta en la dirección contraria, que es la de un deseo finito, que no deja de estar marcado porque no puede ponerse por encima de sí. A ese deseo es al que apunta la interpretación.

En el encuentro con aquella dificultad, que no es otra que la tentación de todo sistema interpretativo de soñar con la coartada de un lenguaje suplementario para el lenguaje que falla en la pesquisa de su propio fundamento -y que se ve tentado por ello a considerarlo como un saber eterno- es como Freud descubre la transferencia sobre la persona del médico, como un modo de resistencia al saber inconsciente. Pero entendiendo con ello, que sin la resistencia al saber, no habría suposición alguna de que hay algo por develar -es decir, la transferencia es, al mismo tiempo, el motor y el impedimento de la praxis analítica (Le Gaufey, 2012). Reconociendo esto, se comprende cómo se anudan transferencia e interpretación. Porque la transferencia "construye" el lugar, de lo que se encontraba ya allí; y la interpretación, es la encargada de borrar al sujeto, como el supuesto portador de un saber atemporal e indefinido, del lugar del Otro, inscribiendo su marca significante. El ser del sujeto, de ahora en adelante, no podrá ir más allá de la marca que lo acompaña y representa. Pero no en su actualidad no hay consistencia alguna que lo singularice como un "sí mismo"- sino que para otras marcas por venir -pero, de la misma manera, sin hacerlo equivaler a ninguna de ellas. La barra que cae así sobre el sujeto, es la imposibilidad misma de que el sujeto se capte sí mismo como deseante. Pero ese punto de reflexividad que falta al sujeto respecto de su deseo, falta también para el Otro. Y de esta manera, la apertura y el cierre otorgan a estos dos dominios, que son el sujeto y el Otro, el modo de su conjunción: circular, mas no recíproca (Lacan, 2008c).

Entre el sujeto cartesiano, como presupuesto del inconsciente, y el Otro, como lugar de la verdad exigido por la dimensión de la palabra, el inconsciente aparece como su corte en acto (Lacan, 2008c). Porque el corte, en sentido topológico, es lo que cierra y pone en continuidad el sujeto y el Otro. El corte en acto del inconsciente, produce un punto que los dos -sujeto y Otro- tienen en común, pero que al mismo tiempo desconocen, por la razón misma de que les pertenece, en un mismo tiempo, a ambos dominios. Se pasa de una a otro sin atravesar un borde. Penetrándose, sin percatarse el uno del otro (Tomei, 1993).

La fragilidad óntica del inconsciente, tan evasivo e inconsistente en su ser, debe considerarse como una cuestión ética. Tomar al inconsciente por la vía del fenómeno, demuestra suficientemente que no es un ente. Desustancializado y desontologizado, el inconsciente es falta en ser. Si para Lacan, el estatuto del inconsciente no es óntico, sino ético (Lacan, 1987), esta ética se inscribe en la falta al nivel óntico y la toma como condición, lo que hace que para la práctica del psicoanálisis, la ética vaya al lugar de la ontología. Porque en esa falta se requiere la decisión, 
el acto, la creación ex-nihilo, en suma, la invención de saber, y respecto a esa invención de un saber por venir es que se produce la resistencia. Porque el inconsciente produce un vacío que determina toda decisión y que entonces creará el espacio donde ella tendrá lugar. Sólo en la medida en que el psicoanalista sostiene el inconsciente a partir de su deseo, se produce la desontologización del inconsciente: el deseo del analista es el deseo de sostener una ficción necesaria, como suposición de saber, para que el inconsciente se manifieste como potencia de ser. A diferencia de las fuerzas mecánicas de la oposición represión y reprimido, esta forma de entender el inconsciente impide llegar a situarlo en una partición estática relativa a lo que es o no es. El inconsciente está tomado en una dinámica, por lo que realizar el saber inconsciente es: donde era el sujeto, adviene el saber. Pero realizándose como saber, de una manera o de otra, ya que depende del deseo del analista-que no es un deseo de infinito. Y mientras no esté realizado, se encuentra suspendido de su posibilidad, indeterminado y al mismo tiempo empujando e insistiendo, sujeto a realizarse. El sujeto es ese surgimiento que, justo antes, como sujeto, no era nada, y que apenas aparece queda fijado en el significante. El inconsciente, como lo que se abre y se cierra, marca el tiempo en el que el sujeto emerge dividido, por nacer del significante (Lacan, 1987, p. 206).

Sin una certeza que conquistar, ni una historia que cumplir, el inconsciente, como lo no realizado, es imposible que sea algo; sólo así es como eso habrá sido un pensamiento.

\section{Referencias}

Aristóteles. (2009). Categorías. Sobre la interpretación (1 ${ }^{\mathrm{a}}$ Ed.). Buenos Aires: Losada.

Aristóteles. (2010). Del Alma (1ª Ed.). Madrid: Gredos.

Aristóteles. (2011). Metafísica (1ª Ed.). Madrid: Gredos.

Agamben, G. (2007). Transmisión de lo inmemorable. In G. Agamben, \& F. Lebenglik (Ed.), La potencia del pensamiento (pp. 189-210). Buenos Aires: Adriana Hidalgo.

Aubenque, P. (1974). El problema del ser en Aristóteles (V. Peña, Trad.). Madrid: Taurus.

Descartes, R. (1987). Los principios de la filosofía (N. Ooms, Trad.). México D.F: Universidad Nacional Autónoma de México.

Descartes, R. (2012). Meditaciones Metafísicas (J. A. Mígues, Trad.). Santiago: Edición electrónica Escuela de Filosofía Universidad ARCIS.

Freud, S. (2008a). La interpretación de los sueños. VII. Sobre la psicología de los procesos oníricos. In $\mathrm{S}$. Freud, Obras Completas de Sigmund Freud (J. L. Etcheverry, Trad., 2a edición, $12^{\mathrm{a}}$ reimpresión ed., Vol. V, pp. 504-598). Buenos Aires: Amorrortu.

Freud, S. (2008b). La sutileza de un acto fallido. In S. Freud, Obras Completas de Sigmund Freud (J. L. Etcheverry, Trad., $2^{\mathrm{a}}$ edición, 12 ${ }^{\mathrm{a}}$ reimpresión ed., Vol. XXII, pp. 230-233). Buenos Aires: Amorrortu.

Freud, S. (2008c). El yo y el ello. In S. Freud, Obras Completas (J. L. Etcheverry, Trad., 2a edición, 12 reimpresión. ed., Vol. XIX, pp. 1-67). Buenos Aires: Amorrortu. Clausuras.

Freud, S. (2012). Introducción del narcisismo. In S. Freud, Obras Completas (J. L. Etcheverry, Trad., $2^{\mathrm{a}}$ edición, $12^{\text {a }}$ reimpresión. ed., Vol. XIV, pp. 1-57). Buenos Aires: Amorrortu.

Heidegger, M. (1996). La época de la imagen del mundo. In M. Heidegger, Caminos de bosque (H. Cortés, \& A. Leyte, Trads.). Madrid: Alianza.

Heidegger, M. (2000). El final de la filosofía y la tarea del pensar. In M. Heidegger, Tiempo y Ser (J. L. Molinuevo, Trad.). Madrid: Tecnos.

Heidegger, M. (2006). Introducción a la investigación fenomenológica (J. J. Garcia Norro, Trad., pp. 25- 57). Madrid: Síntesis.

Heidegger, M. (2009). De la esencia de la verdad. Barcelona, Espanha: Editorial Herder.

Heidegger, M. (2013). La constitución onto-teo-lógica de la metafísica. In M. Heidegger, Identidad y diferencia (H. Cortés, \& A. Leyte, Trads., pp. 15-32). Santiago: Edición electrónica Escuela de Filosofía Universidad ARCIS. Recuperado de www.philosophia.cl.

Lacan, J. (1987). El seminario de Jacques Lacan. Libro 11. Los cuatro conceptos fundamentales del psicoanálisis ( $1^{\text {a }}$ edición ed., J.-A. Miller, Ed., J. L. DelmontMauri, \& J. Sucre, Trads.). Buenos Aires: Paidós.

Lacan, J. (2008a). La instancia de la letra en el insconsciente o la razón desde Freud. In J. Lacan, Escritos 1 (T. Segovia, Trad., $2^{\mathrm{a}}$ edición ed., pp. 461-495). Buenos Aires: Siglo XXI. 
Lacan, J. (2008b). La ciencia y la verdad. In J. Lacan, Escritos 2 (T. Segovia, Trad., $2^{\text {a }}$ edición ed., pp. 813 837). Buenos Aires: Siglo XXI.

Lacan, J. (2008c). Posición del Insconsciente. In J. Lacan, Escritos 2 (T. Segovia, Trad., $2^{\text {a }}$ edición ed., pp. 789809). Buenos Aires: Siglo XXI.

Lacan, J. (2012). La equivocación del sujeto supuesto al saber. In J. Lacan, Otros Escritos (G. T. Esperanza, Trad., $1^{a}$ edición ed., pp. 349-361). Buenos Aires: Paidós.

Le Gaufey, G. (2010). El sujeto según Lacan (M. A. Castañola, \& M. T. Arcos, Trads.). Buenos Aires: El cuenco de plata.

Le Gaufey, G. (2012). La incompletud de lo simbólico. De René Descartes a Jacques Lacan (G. Siciliano Bousquet, Trad.). Buenos Aires: Letra Viva, Ediciones Lecol.

Leibniz, G. W. (2003). Discurso de la Metafísica. In G. W. Leibniz, Escritos Filosóficos (R. Torrettti, T. Zwanck, \& E. de Olaso, Trads., pp. 323-377). Madrid: A. Machado Libros.

Leibniz, G. W. (2003). La profesión de fe del filósofo. In G. W. Leibniz, Escritos Filosóficos (pp. 115-169). Madrid: A. Machado Libros.

Marion, J.-L. (1999). El Idolo y la Distancia (S. Pascual, \& N. Latrille, Trads.). Salamanca: Sígueme.

Marion, J.-L. (2009). Sur la théologie blanche de Descartes ( $2^{\mathrm{a}}$ edición ed.). Paris: PUF.

Nancy, J.-L. (2014). ¿Un sujeto? (F. Alarcón, Trad.). Buenos Aires: La cebra.

Tomei, M. C. (1993). Topología Elemental. Buenos Aires: Gráficas y Servicios.

Vallejo, M. (2014). La seducción freudiana: (1895-1897) Un ensayo de genética textual. Buenos Aires: Letra Viva.

\section{Endereço para correspondência:}

\section{Gianfranco Cattaneo}

Endereço: Calle Quillota, $n^{\circ}$ 980, 5to piso, Torre D. Viña del Mar, Región de Valparaíso, Chile.

E-mail: gcattaneo@unab.com 